\title{
Assessing Collaboration and Knowledge Flow on Coatings of Metallic Glasses Obtained From Thermal Spraying Processes Using Bibliometrics and Science Mapping
}

\author{
Douglas Henrique Milanez ${ }^{a, b, c *}$, Braulio Salumao de Oliveira ${ }^{a}$, Everard Christiaan Marie Noyons ${ }^{c}$, \\ Leandro Innocentini Lopes Faria ${ }^{a}$, Walter José Botta \\ ${ }^{a}$ Universidade Federal de São Carlos, Departamento de Engenharia de Materiais, Núcleo de \\ Informação Tecnológica em Materiais, Rod. Washington Luis km 235, São Carlos, SP, Brazil \\ ${ }^{b}$ Universidade Federal de São Carlos, Departamento de Engenharia de Materiais, Laboratório de \\ Materiais Amorfos e Nanoestruturados, Rod. Washington Luis km 235, São Carlos, SP, Brazil \\ 'Leiden University, Centre for Science and Technology Studies, 2300AX, Leiden, Netherlands
}

Received: March 17, 2017; Revised: September 15, 2017; Accepted: October 02, 2017

Coatings of amorphous metallic alloys can be obtained using different thermal spraying processes, such as HVOF, plasma spraying, cold spraying and others. Although many studies focused on investigating scientific issues concerning apply amorphous metallic coatings using thermal spraying, less attention have been paid to evaluate how research institutes and companies are collaborating and influencing each other to promote new technologies. In this paper, we assessed the collaboration of organizations and the knowledge flow on this relatively new field using bibliometrics and science mapping. The method relies on scientific publications indexed in Web of Science and clustered into research areas using the CWTS Publication-level Classification System. These results provide useful insights about how players are organized and may be used in the context of R\&D management, science policy and decision making.

Keywords: S\&T indicators, non-crystalline metals, science mapping, technological forecasting.

\section{Introduction}

\subsection{Amorphous metallic alloys applied by thermal spraying processes}

Amorphous or glass metallic alloys are a striking class of non-crystalline materials with great potential for industrial application and technological innovations due to their particular mechanical, magnetic or electrical properties. This special class of metals are generally obtained by the combination of engineered compositions - usually involving more than three metallic elements with large atomic size ratios - with processes that provides high cooling rates $\left(10^{2}-10^{6} \mathrm{~K} / \mathrm{s}\right)$ in a manner that the disordered atomic configuration found in the melted liquid is maintained down to room temperature ${ }^{1,2}$. Indeed, determining the glass-forming ability, the critical cooling rate and the final thickness of non-crystallinity is always a subject of research ${ }^{3}$. Furthermore, usual application of glassy metals includes pressure sensors for automobile industry and soft magnetic cores ${ }^{1}$.

Recently, thermal spraying processes have been applied to produce coatings of metallic glasses in order to enhance the wear and corrosion resistance of metallic components working under severe operational condition, such as in the oil and gas industry ${ }^{4-11}$. In the process, a feedstock material is heated by electrical or chemical means and the spray of molten or semi-molten particles is directed or accelerated

*e-mail: douglasmilanez@yahoo.com.br to a substrate to form the coating. Figure 1 provides a comparison of various thermal spray processes in terms of particle temperature and velocity. An interesting historical overview over these processes is found in Kuroda et al. .

Plasma spraying, wire arc spraying, flame spraying, and high velocity oxygen fuel (HVOF) are examples of thermal spraying techniques already available on the markett, ${ }^{6,8,12-14}$. Another relevant thermal spraying process is the high velocity air fuel (HVAF), which use other gases instead of oxygen and prevent the formation of oxide inclusions in the final coating. Finally, although they do not achieve high temperatures, warm-spraying and cold-spraying can also be categorized as thermal spraying process because they mainly exploit the velocity of particles. Both can be place in earlier stage of development than HVOF, because they are not used widely by industry yet due to the high costs involve in the process $^{9,15}$. However, cold-spraying have achieved space in the aeronautic and aerospace industry, due to the low porosity achieved and high quality of the final coating 9 .

Studies have investigated the metallic glass coating performance and process parameters (temperature, velocity and cooling rates) of thermal spraying process to minimize or avoid porosity, oxide inclusion and enhance coating/substrate adhesion $^{4,6-10,12}$. However, less attention has been paid to assessing the impact of these studies by understanding how research institutes and companies are organizing themselves to face the scientific and technological challenges, and which 


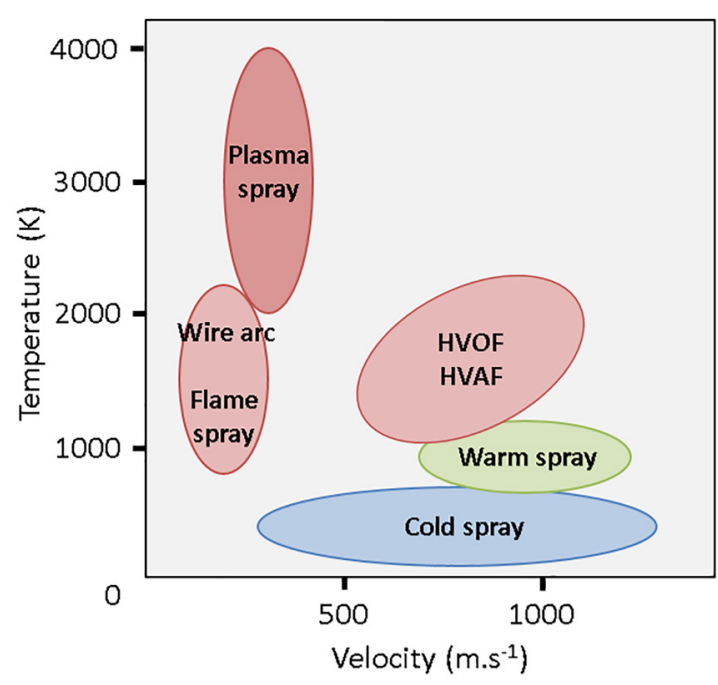

Figure 1. Examples of thermal spraying processes in terms of temperature and velocity of the particle. Source: adapted from Kuroda et al. (2008)

ones dominate the flow of knowledge in this area. Bibliometric analysis and science maps may provide insightful indicators to answer these questions and to support the R\&D management, scientific policies and decision making of stakeholders involved in the development of new amorphous metallic coatings ${ }^{16-21}$.

This study aims at analyzing the collaboration and the knowledge flow on amorphous metallic coatings applied by thermal spraying in order to understand the panorama of researching, the main thermal spraying processes used and how organizations has contributed to the development of this area. The analysis involves traditional bibliometric indicators, co-authorship-based maps and citation analysis. In the following section, we provide concepts on bibliometrics and science mapping. Next, we explain the experimental procedure used to retrieve and analyze the indicators, and we present and discuss the results. Finally, we sum up all remarks and outcomes in the conclusion section.

\subsection{Bibliometric analysis and science maps}

Currently, new technological development has become more complex, team-based and science-dependent ${ }^{21-23}$, especially when it involves advanced materials and new processes, such as amorphous metallic alloys and thermal spraying processes. Due to the high volume of data and information available in high-quality scientific databases, bibliometrics and science maps can be used to render data into actionable insights ${ }^{19,21,24-27}$. Bibliometrics is defined as statistical techniques and methods to measure of the registered technical and scientific communication ${ }^{19,21,25}$. Science maps are spatial representations of relationships among bibliometric elements - such as authors, institutions, key-words, classifications, disciplines etc ${ }^{16,18,27}$.

Science mapping is a hot topic since it has a visual appeal and enables striking interpretations. For instance, a still open question is how to structure science. Many approaches have been proposed to represent science in maps, including how elements within these maps should be positioned, organized and clustered ${ }^{17,18,27-30}$. The most well know maps of science includes maps by experts, reference paper maps, journal maps and journal category (disciplines) maps - Klavans and Boyack ${ }^{28}$ discussed the essence of each type and proposed a "consensus map of science" by analyzing 20 existing maps of science. In this paper we use a specific Publication-level Classification System $^{31}$, which can be represented in maps, to retrieve relevant publications about our topic of interest. Previous research showed us that delineating a sample of publications using this system is more effective than regular Boolean searches in databases because it enhances the precision of the search ${ }^{32}$.

Two bibliometric concepts that deserve more attention in the context of this study are co-authorship and citation analysis. The first one assesses the co-occurrence of different authors, organizations or countries in the same publication resulting in a node-edge network maps when many publications are considered. These maps usually are interpreted as to how the elements are distributed and clustered ${ }^{19,29}$. Citation analysis calculates the frequency in which papers are cited by other papers. This can also be represented in maps and large-scale patterns can be observed, which might indicate the knowledge flow between these papers. Citations also allow the evaluation of impact and as such the basis for other indicators, such as Journal's Impact Factor and researchers' h-index. Hence, a measure may involve organizations citing each other to define the most influential ones - as we do in this study ${ }^{21,29,33,34}$.

The number of bibliometric studies in amorphous metals and thermal spraying is scarce. Khor and $\mathrm{Yu}^{35}$ provided a set of bibliometric indicators concerning thermal spraying technology using the bibliographic data of publications published from 1995 to 2014 and indexed in the Scopus and the Web of Science databases, two of the most relevant databases for developing indicators. Their panorama included the scholarly output and impact, leading countries and institutions, besides maps of leading journals, technical terms and institutions. However, they did not analyze properly the implications and trends observed in the indicators and neither considered amorphous/glassy alloys as a target of investigation. Finally, Milanez et al. ${ }^{36}$ assessed the patent activity on metallic glasses and observed the stage of development of technologies based in these special alloys, the main applications of new developments, the relevant role of universities, and which alloys companies and research institutions have put their efforts.

\section{Data and Method}

\subsection{Retrieving publication data}

Defining a set of publications to perform bibliometric analysis is always a challenging task since publications 
are difficult to be classified using traditional librarianbased methods, such as the classical journal classification regularly used in bibliographic databases. This study relies on bibliometric indicators of scientific publications indexed in the Web of Science database and clustered according to the Publication-level Classification System develop by Centre for Science and Technology Studies (CWTS) ${ }^{31}$. In this classification system, articles, letters and reviews indexed in Science Citation Index Expanded and the Social Science Citation Index are clustered into research areas based on direct citation relations and other criteria defined by the authors. Around 18 Million of publication published between 2000 and 2015 are processed in the current version and a publication can be addressed into one cluster only. A single research area can contain hundreds or thousands of publications clustered. The use of this publication-level classification system proved to be effective to enhance the precision on information retrieving task in earlier study ${ }^{32}$.

Figure 2 depicts the procedure for retrieving information, and to develop, visualize and analyze the indicators. The procedure sets off with seeking publications of amorphous/ glassy metals and thermal spraying in the CWTS Publicationlevel Classification System using a key-word based search expression presented in Table 1. We conducted the search separately and we looked for key-words in titles, abstracts or author's keywords. Besides the total of publications retrieved, the classification system also provides the research areas that these publications belong.

As already observed in previous research ${ }^{32}$, a variety of research areas is usually retrieved. Nevertheless, in the case of amorphous/glassy metallic alloys, only one research area already covered $71.5 \%$ of the total publications retrieved by the search expression. After analyzing the content of this specific research area (the entire cluster), we could confirm that it concerns specifically on non-crystalline metals, one of the subjects of this study. This research area comprises a total of 13,541 publications, and we interpreted it as a nucleus research area for amorphous/glassy metals. Each of the other 521 research areas covered less $1.5 \%$ of the total publications retrieved by the search expression and were therefore discarded. In the case of thermal spraying, one research area also highlighted because it contained 52.9\% of the total publication retrieved by its search expression. We also verified the content of this research area and could confirm that, indeed, it focuses on coatings obtained by thermal spraying process. We also discard the other research areas retrieved by the thermal spraying search expression. Thus, at the end of this first step from Figure 2, we have two main research areas: one about amorphous/glassy metals and other about coatings/thermal spraying.

The next step was performing a "cross searching", i. e. we sought for amorphous/glassy metals publication in the coating/thermal spraying research area using the amorphous/ glassy metals search expression; and we looked for papers

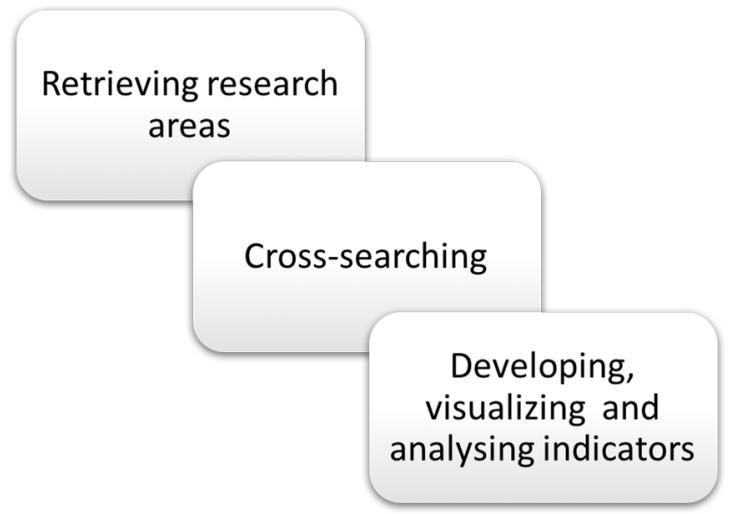

Figure 2. Procedure for retrieving information and obtaining indicators. Source: developed by the authors.

in the amorphous/glassy metals using the thermal spraying search expression (Table 1). The final sample of retrieved publications comprised 169 publications.

\subsection{Developing the indicators}

The last step of the procedure involves indicators (Figure 2). We verified the evolution of publications to each thermal spraying processes (HVOF, Plasma Spraying, etc.) that have been used to produce coatings of metallic glasses. We also developed a map based on co-authorship to analyze the collaboration among organizations. To identify the most influencing organizations, we assembled a map based on citation. All maps were visualized and analysed with support of VOSviewer software ${ }^{37,38}$. To assess the role and impact of organizations (universities, research institutes and companies), we colored the map nodes according to different criteria:

- Country of the organizations;

- Proportion of collaborative publications ( $\left.\mathrm{PP}_{\text {collab }}\right)^{\mathrm{a}}$, which indicates the proportion of publications of an organization that have been coauthored with one or more other organizations;

- Proportion of collaborative publications with industry $\left(\mathrm{PP}_{\text {ind }}\right)^{\mathrm{a}}$, which indicates the proportion of an organization's publications that have been co-authored by industry;

- Companies in the maps and we assume that they might be looking for new technologies of amorphous/glassy metallic coatings applied by thermal spraying process;

- Number of publications concerning the main thermal spraying processes (HVOF, Plasma Spraying, Wire Arc Spraying, Cold Spraying), which was obtained by performing searches using specific process terms found in Table 1.

The criterion used to color the citation map is the average number of citations of the publications an organization had, normalized by field and publication year (MNCS) ${ }^{\text {a }}$. As described by Waltman et al. ${ }^{39}$, this indicator is calculated for 
Table 1. Key-words used to search for amorphous/glassy metals and thermal spraying publications.

\begin{tabular}{|c|c|c|}
\hline Search Expression & $\begin{array}{l}\text { \# publications } \\
\text { retrieved* }\end{array}$ & $\begin{array}{l}\text { \# research areas } \\
\text { retrieved }\end{array}$ \\
\hline $\begin{array}{l}\text { "amorphous*metal*" OR "amorphous*alloy*" OR "metal* glass*" OR "alloy*glass*" } \\
\text { OR "glass*metal*" OR "glass*alloy*" }\end{array}$ & 14,169 & 522 \\
\hline $\begin{array}{l}\text { "thermal spray*" OR "plasma spray*" OR "wire arc spray*" OR "flame spray*" OR } \\
\text { "flame aerosol*" OR "detonation spray*" OR "HVOF*" OR "high velocity oxy-fuel*" } \\
\text { OR "high velocity oxygen fuel*" OR "high velocity oxy fuel*" OR "HP-HVOF*" OR } \\
\text { "high pressure high velocity oxy-fuel*" OR "high pressure high velocity oxygen fuel*" } \\
\text { OR "high pressure high velocity oxy fuel*" OR "high pressure HVOF*" OR "HVAF*" } \\
\text { OR "high velocity air-fuel*" OR "high velocity air fuel*" OR "LVOF*" OR "low } \\
\text { velocity oxy-fuel*" OR "low velocity oxygen fuel*" OR "low velocity oxy fuel*" OR } \\
\text { "warm*spray*" OR "cold*spray*" }\end{array}$ & 10,285 & 411 \\
\hline
\end{tabular}

*we only considered scientific papers published from 2000 to 2015.

$* *$ the size of each research areas varies in terms of number of publication it clusters.

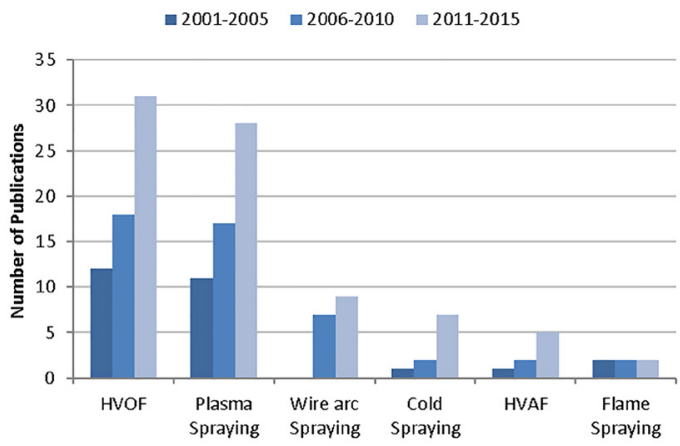

Figure 3. Number of publication of thermal spraying processes used to obtain amorphous metallic coatings, accumulated in different the periods. Source: Web of Science and CWTS Pub-level Classification System.

each publication of an organization considering the actual number of citations and the expected number of citations, which is determined by the average number of citations of the publication sample analyzed. Since much details could not be included in this paper, we provide online versions of these maps to explore in detail ${ }^{\mathrm{b}}$.

\section{Results and Discussion}

\subsection{Thermal spraying processes and collaboration analysis}

HVOF and Plasma Spraying are the most used thermal spraying processes to obtain glassy metal coatings. According to Figure 3, both experienced a rapid increase in the number of publications and this might be associated to the fact that they have been highly researched in the past and are

\footnotetext{
$\overline{\text { a These three indicators are calculated according to the procedure described }}$ in Leiden Ranking ${ }^{39,41}$.

${ }^{\text {b}}$ You may see the map in: $<$ http://www.vosviewer.com/vosviewer.php?map=https:// www.cwts.nl/research/milanez2017/Networking_analysis_VOS_map_final. txt\&network=https://www.cwts.nl/research/milanez2017/Networking_analysis VOS net final.txt\&n lines $=500>$. You can also download VOSviewer in: $<\mathrm{http}: / / \mathrm{ww}$ w.vosviewer.com/ $>$ to open the file.
}

widely dominated by the industry. Wire Arc Spraying, Cold Spraying and HVAF have also grown in terms of research dedicated to them unlike Flame Spraying, which leveled out in the periods analysed. Furthermore, only one publication regarding warm-spraying and one about low velocity oxy-fuel was obtained, published respectively in 2008 and 2014, thus they were not included in the final indicator chart.

We verified that $40.2 \%$ of the retrieved publications were published by only one organization. $41.2 \%$ involved national collaboration (two or more organizations from the same country) and $18.3 \%$ shared international collaborations. The collaboration analysis based on co-authorship of organizations offers striking highlights on coatings of amorphous metals applied by thermal spraying processes. A total of 137 organizations have at least one publication. The Chinese Academy Science (China), Hanyang University (South Korea), Osaka University (Japan), University of Technology at Belfort and Montbéliard (France) and Huazhong University of Science and Technology (China) are the most productive ones.

Figure 4 provides an overview of all organizations (universities, research institutes and companies) that constitutes the collaboration. In the map, node's size is proportional to the total number of publication of each organization while the ties' thickness relates to the number of publication the organizations share or to the number of citations that the organizations have made to each other's publications. Nodes were colored according to organization's country and the map shows clearly that there are clusters formed basically by organizations from the same country. A total of 20 organizations did not collaborate and nine had only one partner of research. Five clusters (from A to E) stand out in Figure 4. They comprise organizations basically from the USA (A), France (B), China (C), Korea (D), and JapanChina (E). Indeed, China accounted for the highest number of organizations (31 nodes) in the map followed by the USA (27 nodes). Moreover, there is no central organization in the map, only in their specific cluster of organizations. 


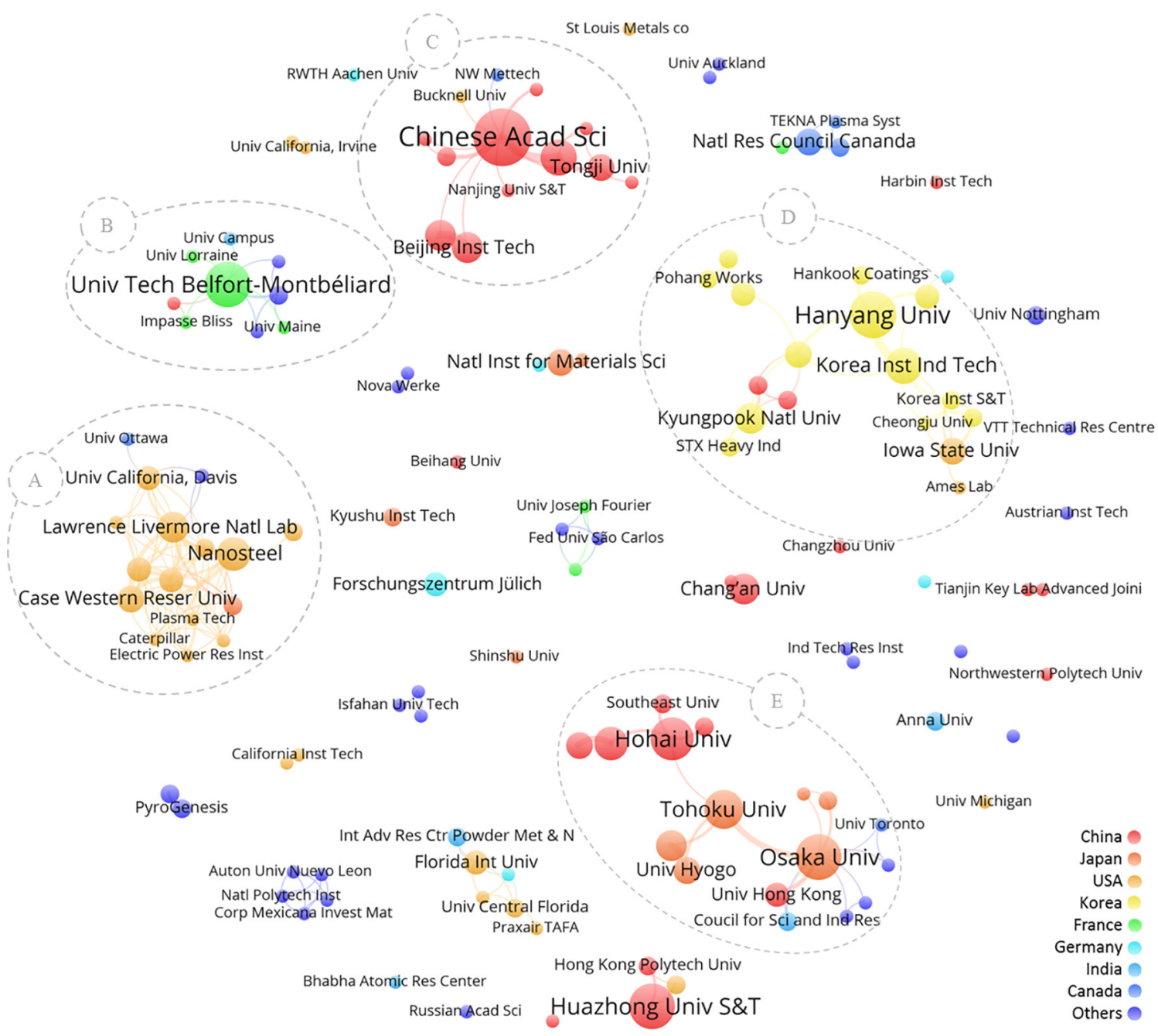

Figure 4. Collaboration map of the organizations involved in the research of thermal spraying processes applied to coatings of amorphous/ glassy metals. The colors indicate the subgroups and in blue are the smaller ones. Source: Web of Science and CWTS Pub-level Classification System.

Figure 5 contains three maps (I, II and III) from the same collaborations observed on Figure 4, excluding the non-collaborative organizations. Map I shows that the organizations tend to collaborate intensively with their partners, probably because they have a low number of publications in general. Among the most productive organizations (in terms of total number of publications), Osaka University (Japan) and Hanyang University (South Korea) are highly collaborative while the University of Technology at Belfort and Montbéliard (France) and Huazhong University of Science and Technology (China) collaborated less (Map I from Figure 5). These organizations have a central role

\footnotetext{
' The companies are: the Canadian NW Mettech Corp. and TEKNA Plasma Syst Inc., the China National Aviation Ind., the Greek PyroGenesis SA, the Iranian Poudrafshan Co., the Japanese Nakayama Steel Works ltd. and the Topy Ind. Co. Ltd., the Korean Hankook Coatings, Pohang Works and STX Heavy Ind. Co., the Swiss Nova Werke Ag. And the American ASB Ind. Inc., Caterpillar Inc., GE Global Research, Nanosteel Co., Plasma Tech Inc., Praxair TAFA, Strategic Analytics, and V\&A Engineering.
}

to the advances on amorphous/glassy coatings applied by thermal spraying in their country.

A total of 19 companies are mapped ${ }^{c}$. Although part of the companies is distributed all over the map (Map III, Figure 5), there is a concentration (six companies) in the cluster of the USA organizations and, consequently, this cluster tends to have high $\mathrm{PP}_{\text {ind }}$ values. This result suggest that the USA may have been leading new scientific-based technological developments on amorphous/glassy metallic coatings applied by thermal spraying since the more organizations collaborate with industry the higher is the chance of new technologies outcome $\mathrm{e}^{22,40}$.

Figure 6 provides an overall analysis of thermal spraying processes investigated by organizations. All clusters of organizations (Figure 4) put effort on HVOF process. However, some institutions outstand, (e.g., University of Petroleum of East China, the Chinese Academy Science, Huazhong University Science and Technology, and the French 


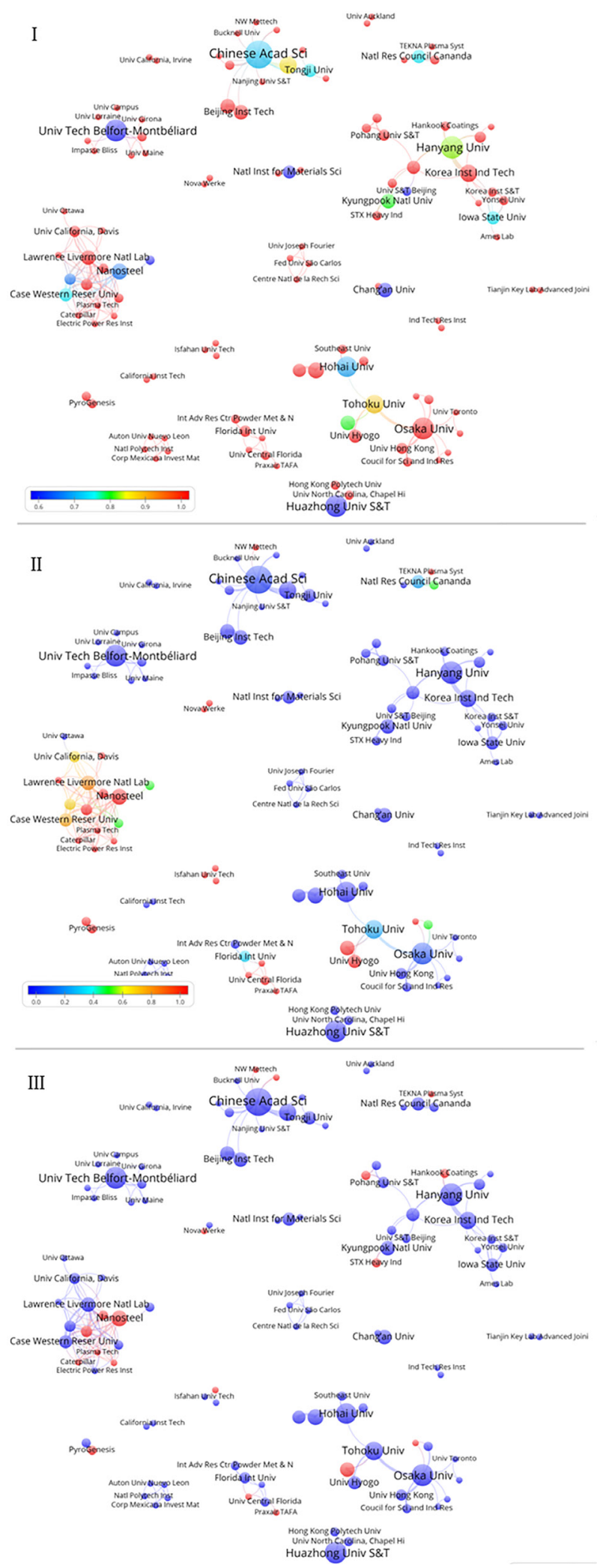

Figure 5. Collaboration maps: (I) proportion of organization's publications co-authored with one or more other organizations; (II) proportion of organization's publications co-authored by industry; (III) companies (in red). We eliminated non-collaborative organizations. Source: Web of Science and CWTS Pub-level Classification System. 


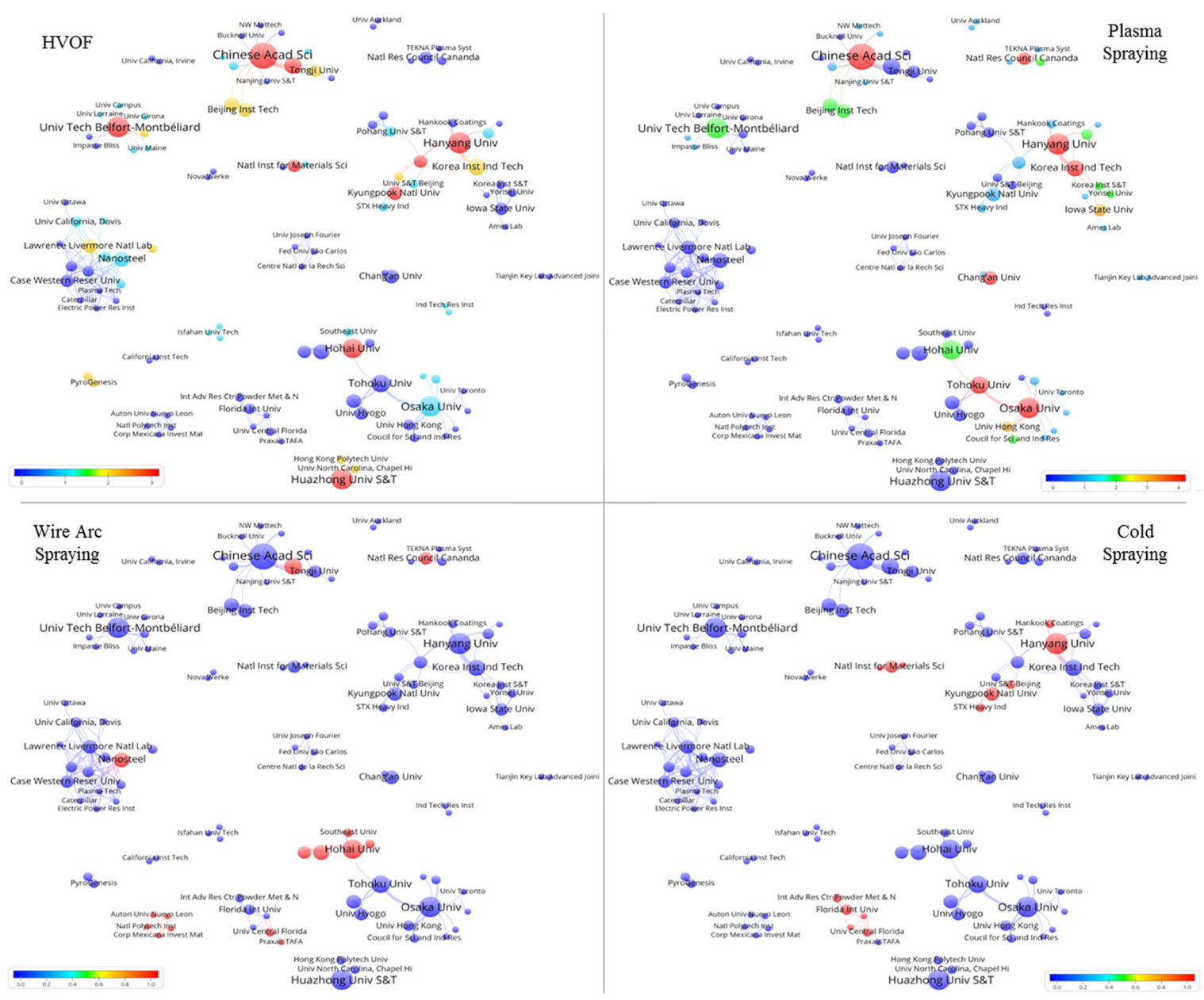

Figure 6. Collaboration maps on different thermal spraying processes. Organizations were collared proportionally to their number of publications on each process. Source: Web of Science and CWTS Pub-level Classification System.

University of Technology at Belfort and Montbéliard). The universities and research institutes from Korea carried out scientific research on Plasma Spraying and Cold Spraying whereas the Japanese Osaka University and Tohoku University investigated mainly Plasma Spraying. In the case of Cold Spraying process, we verify that the Florida International University (USA), the Institute of Advanced Research Centre for Powder Metallurgy \& New Materials (India) and the National Institute for Materials Science (Japan) highlights in publications. Additionally, even though Hohai University published some few researches on HVOF and Plasma Spraying, the cluster of Chinese organizations tackled about Wire Arc Spraying process.

The knowledge flow measured by the citation analysis can be viewed in Figure 7. Note that the position of each organization is the same as the maps from Figures 4, 5 and 6, but the links are now the citation between their publications. The organizations are colored according to the average number of citations of their publications normalized for field and publication year (MNCS). An MNCS value of two means that the publications of an organization have been cited twice above the average of their field and publication year. Consequently, the most influencing organizations in the research of amorphous metallic coatings obtained by thermal spraying processes are highlighted from green to red. However, the drawback of this indicator is the fact that one highly cited publication influences a lot in the final analysis and this occurred in our map to organizations with only one publication (all in red color). Interestingly, four American companies co-authored these unique but highly cited papers.

If we consider the total number of publication to minimize the bias of the MNCS indicator, we can point the Huazhong University of Science and Technology and the Chinese Academy of Science as the most influential in the network. Considering the clusters of organizations (Figure 4), we also can conclude that the American, the Chinese and the Sino-Japanese clusters are those which influence most research on coatings of metallic glasses applied by thermal spraying processes. Furthermore, HVOF is the thermal spraying process that most occurred in publications from these organizations, which also indicates this process 


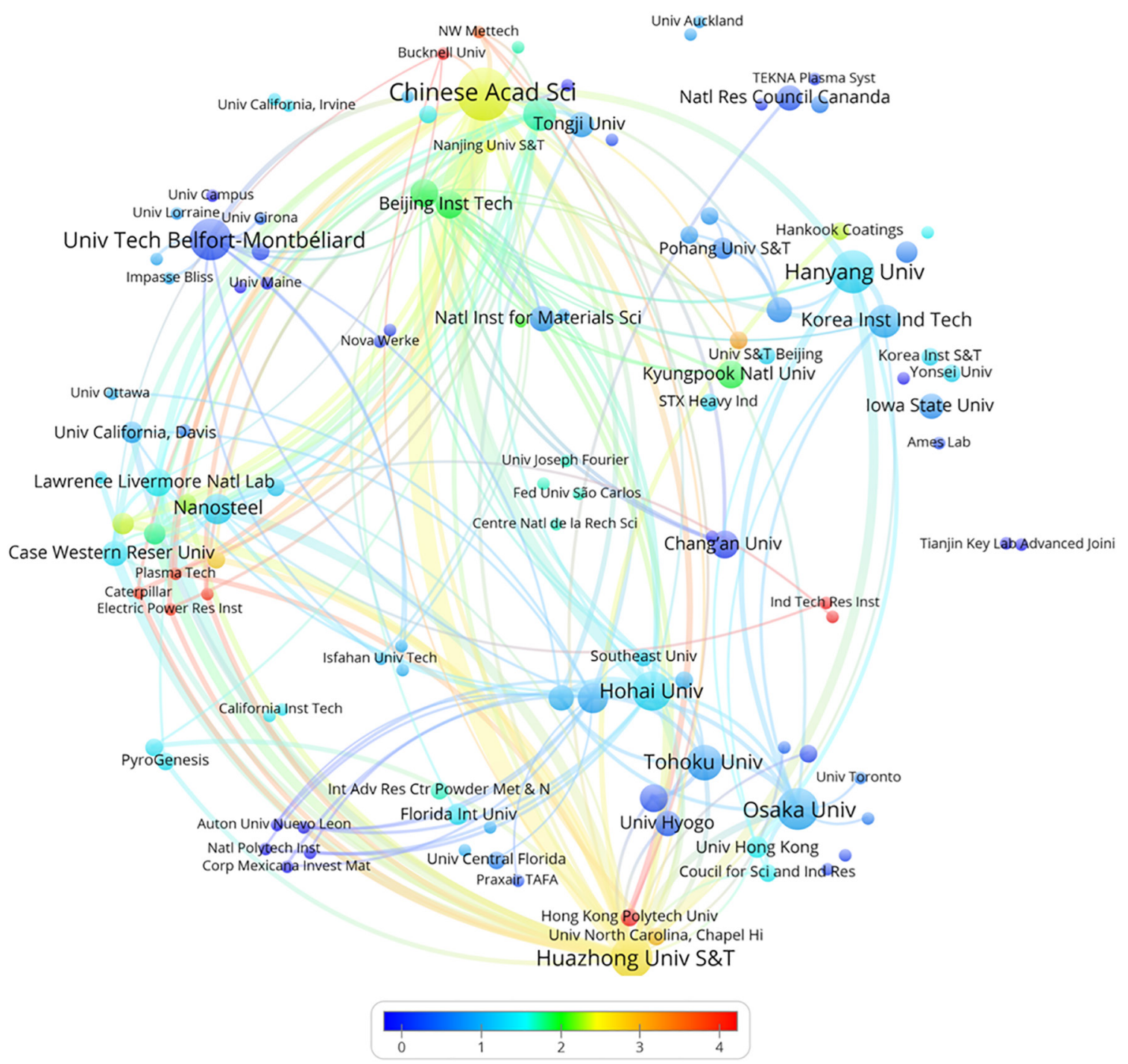

Figure 7. Citation map of organizations between organization's publications. The nodes are colored according to the MNCS indicator. Source: Web of Science and CWTS Pub-level Classification System.

as the most relevant for the development of amorphous metallic coatings.

\section{Conclusion}

In this paper, we evaluate the scientific research on amorphous metallic coatings obtained by thermal spraying processes. We focus on collaboration and citation analysis of organizations as well as the evolution of publication of the main processes used to obtain the coatings. The final indicators are visualized by multidimensional maps and the panorama provided can support $R \& D$ management, decision making and science policy.

The results suggest that the use of thermal spraying to obtain amorphous metallic coatings is still emerging. Plasma spraying, wire arc spraying, flame spraying, and high velocity oxygen fuel (HVOF) are thermal spraying techniques already available on the market, even though they are still topic of research for amorphous metals coatings. Nonetheless, the outcomes suggest that the scientific knowledge on coatings of metallic glasses tend to be more dependent on HVOFfocused research than other techniques.

The preference of organizations to cooperate with partners geographically near is recurrent in science. However, the USA cluster of organizations highlights because they account with more companies on their cluster with outstanding values of proportion of collaborative publications with industry. We can also conclude that companies are highly interesting on research of amorphous coating applied by thermal spraying, considering their presence in the whole net. Furthermore, the Chinese and the American cluster of organizations have impacted more on research activities recently as their set 
of publications were most cited among the papers from the sample analyzed.

Finally, even though citations and publications register only part of a most complex reality, our assessment provides good indications on preferred thermal spraying process, universities and research institutes. The method based on bibliometrics and science mapping can be applied to other subjects of research, although their particularities must be taken into account.

\section{Acknowledgements}

The authors are thankful for the funding support provided by the Sao Paulo Research Foundation (FAPESP) - process numbers: 2016/07292-5 and 2015/18878-8, the Brazilian Coordination for the Improvement of Higher Education Personal (CAPES) and the Graduate Program in Materials Science and Engineering (PPGCEM).

\section{References}

1. Inoue A, Takeuchi A. Recent development and application products of bulk glassy alloys. Acta Materialia. 2011;59(6):2243-2267.

2. Inoue A. Stabilization of metallic supercooled liquid and bulk amorphous alloys. Acta Materialia. 2000;48(1):279-306.

3. Lu ZP, Liu CT. A new glass-forming ability criterion for bulk metallic glasses. Acta Materialia. 2002;50(13):3501-3512.

4. Guo Y, Koga GY, Jorge Jr. AM, Savoie S, Schulz R, Kiminami $\mathrm{CS}$, et al. Microstructural investigation of $\mathrm{Fe}-\mathrm{Cr}-\mathrm{Nb}-\mathrm{B}$ amorphous/ nanocrystalline coating produced by HVOF. Materials \& Design. 2016;111:608-615.

5. Liu XQ, Zheng YG, Chang XC, Hou WL, Wang JQ, Tang Z, et al. Microstructure and properties of Fe-based amorphous metallic coating produced by high velocity axial plasma spraying. Journal of Alloys and Compounds. 2009;484(1-2):300-307.

6. Guo RQ, Zhang C, Chen Q, Yang Y, Li N, Liu L. Study of structure and corrosion resistance of Fe-based amorphous coatings prepared by HVAF and HVOF. Corrosion Science. 2011;53(7):2351-2356.

7. Ni HS, Liu XH, Chang XC, Hou WL, Liu W, Wang JQ. High performance amorphous steel coating prepared by HVOF thermal spraying. Journal of Alloys and Compounds. 2009;467(1-2):163167.

8. Zhou Z, Wang L, Wang FC, Zhang HF, Liu YB, Xu SH. Formation and corrosion behavior of Fe-based amorphous metallic coatings by HVOF thermal spraying. Surface and Coatings Technology. 2009;204(5):563-570.

9. Kuroda S, Kawakita J, Watanabe M, Katanoda H. Warm spraying-a novel coating process based on high-velocity impact of solid particles. Science and Technology of Advanced Materials. 2008;9(3):033002.

10. Pawlowski L. The Science and Engineering of Thermal Spray Coatings. Hoboken: John Wiley \& Sons; 2008.
11. Markets and Martkets. Protective Coating Resins Market by type (Epoxy, Alkyd, Acrylic, Polyurethane), Formulation (Solvent-borne, Water-borne, and Powder), End-use industry (Industrial, Oil \& gas, Marine, Automotive, Mining) and Region - Global Forecast to 2021. 2016. Available from: <http://www. marketsandmarkets.com/Market-Reports/protective-coatingsmarket-125206748.html>. Access in: 21/1/2017.

12. Simunovic K. Thermal spraying. Welding Engineering and Technology, v. Eolss. net; 2010. Available from: $<$ http://www. eolss.net/sample-chapters/c05/e6-171-17-00.pdf $>$. Access in: $17 / 10 / 2017$

13. Zhang H, Xie Y, Huang L, Huang S, Zheng X, Chen G. Effect of feedstock particle sizes on wear resistance of plasma sprayed Fe-based amorphous coatings. Surface \& Coatings Technology. 2014;258:495-502

14. Stöver D, Pracht G, Lehmann H, Dietrich M, Döring JE, Vaßen R. New material concepts for the next generation of plasmasprayed thermal barrier coatings. Journal of Thermal Spray Technology. 2004;13(1):76-83.

15. Moridi A, Hassani-Gangaraj SM, Guagliano M, Dao M. Cold spray coating: review of material systems and future perspectives. Surface Engineering. 2014;30(6):369-395.

16. Eck NJ, Waltman L, Noyons ECM, Buter RK. Automatic term identification for bibliometric mapping. Scientometrics. 2010;82(3):581-596.

17. Chen C, Leydesdorff L. Patterns of connections and movements in dual-map overlays: A new method of publication portfolio analysis. Journal of the Association for Information Science and Technology. 2014;65(2):334-351.

18. Börner K, Theriault TN, Boyack KW. Mapping science introduction: Past, Present and Future. Bulletin of the Association for Information Science and Technology. 2015;41(2):12-16.

19. Okubo Y. Bibliometric Indicators and Analysis of Research Systems: Methods and Examples. OECD Science, Technology and Industry Working Papers, No. 1997/01, Paris: OECD Publishing; 1997.

20. Martino JP. A review of selected recent advances in technological forecasting. Technological Forecasting and Social Change. 2003;70(8):719-733.

21. Van Raan AFJ. Advances in bibliometric analysis: research performance assessment and science mapping. In: Blockmans W, Engwall L, Weaire D, eds. Bibliometrics: Use and abuse in the review of research performance. Portland: Portland Press; 2014. p. $17-28$.

22. Tijssen RJW. Measuring and evaluating science-technology connections and interactions: towards international statistics. In: Moed HF, Glänzel W, Schmoch U, eds. Handbook of quantitative science and technology research: the use of publication and patent statistics in studies of S\&T systems. New York: Kluwer Academic Publishers; 2004. p. 695-715.

23. Van Raan AFJ. Sleeping beauties cited in patents: Is there also a dormitory of inventions? Scientometrics. 2017;110(3):11231156.

24. Waltman L, van Eck NJ, Noyons ECM. A unified approach to mapping and clustering of bibliometric networks. Journal of Informetrics. 2010;4(4):629-635. 
25. Van Raan AFJ. Meansuring Science. In: Moed HF, Glänzel W, Schmoch U, eds. Handbook of quantitative science and technology research: the use of publication and patent statistics in studies of S\&T systems. New York: Kluwer Academic Publishers; 2004. p. $19-50$.

26. Leydesdorff L, Wouters P, Bornmann L. Professional and citizen bibliometrics: complementarities and ambivalences in the development and use of indicators--a state-of-the-art report. Scientometrics. 2016;109(3):2129-2150.

27. Zhang Y, Zhang G, Zhu D, Lu J. Scientific evolutionary pathways: Identifying and visualizing relationships for scientific topics. Journal of the American Society for Information Science and Technology. 2017;68(8):1925-1939.

28. Klavans R, Boyack KW. Toward a consensus map of science. Journal of the American Society for Information Science and Technology. 2009;60(3):455-476.

29. Rafols I, Porter AL, Leydesdorff L. Science overlay maps: A new tool for research policy and library management. Journal of the American Society for Information Science and Technology. 2010;61(9):1871-1887.

30. Leydesdorff L, Kushnir D, Rafols I. Interactive overlay maps for US patent (USPTO) data based on International Patent Classification (IPC). Scientometrics. 2014;98(3):1583-1599.

31. Waltman L, van Eck NJ. A new methodology for constructing a publication-level classification system of science. Journal of the American Society for Information Science and Technology. 2012;63(12):2378-2392.

32. Milanez DH, Noyons ECM, Faria LIL. A delineating procedure to retrieve relevant publication data in research areas: the case of nanocellulose. Scientometrics. 2016;107(2):627-643.
33. Noyons ECM, Moed HF, Luwel M. Combining mapping and citation analysis for evaluative bibliometric purposes: A bibliometric study. Journal of the American Society for Information Science and Technology. 1999;50(2):115-131.

34. Van Raan AFJ. Patent Citations Analysis and Its Value in Research Evaluation: A Review and a New Approach to Map Technology-relevant Research. Journal of Data and Information Science. 2017;2(1):13-50.

35. Khor KA, Yu LG. Global Research Trends in Thermal Sprayed Coatings Technology Analyzed with Bibliometrics Tools. Journal of Thermal Spray Technology. 2015;24(8):1346-1354.

36. Milanez DH, Faria LIL, Leiva DR, Kiminami CS, Botta WJ. Assessing technological developments in amorphous/glassy metallic alloys using patent indicators. Journal of Alloys and Compounds. 2017;716:330-335.

37. CWTS. VOSviewer. 2017. Available from: <http://www. vosviewer.com/>. Access in: 15/9/2017.

38. Van Eck NJ, Waltman L. Text mining and visualization using VOSviewer. ISSI Newsletter. 2011;7(3):50-54.

39. Waltman L, Calero-Medina C, Kosten J, Noyons ECM, Tijssen RJW, van Eck NJ, et al. The Leiden Ranking 2011/2012: Data collection, indicators, and interpretation. Journal of the American Society for Information Science and Technology. 2012;63(12):2419-2432.

40. Tijssen RJW, van Leeuwen TN. Measuring impacts of academic science on industrial research: A citation-based approach. Scientometrics. 2006;66(1):55-69.

41. CWTS. Leiden Ranking 2017 - Moving beyond just ranking. Available from: $<$ http://www.leidenranking.com/>. Access in: 15/9/2017. 